\section{Os dançarinos em cadeira de rodas no con- texto dos espetáculos}

\section{The wheelchair dancer within the context of spectacles}

Keyla Ferrari Lopes ${ }^{1}$

Paulo Ferreira de Araújo ${ }^{1}$

\section{Resumo}

O presente artigo tem como objetivo refletir sobre a participação e inclusão social dos dançarinos em cadeira de rodas no contexto de apresentações e espetáculos abertos ao público. Utilizamos a pesquisa qualitativa, com entrevista aplicada a um grupo de doze dançarinos de cadeira de rodas que participaram regularmente de apresentações e espetáculos. Recorremos aos procedimentos de análise de conteúdo a fim de classificar indicadores para uma discussão e reflexão acima das respostas dos dançarinos. Os resultados acerca dos discursos dos dançarinos em cadeira de rodas destacam a dança como produto artístico não enfocando a deficiência, fortalecendo no contexto do palco e na relação estabelecida entre dançarino/ expectador uma nova identidade social, a identidade artística.

\section{Palavras-chave}

Deficiência; Dança em cadeira de rodas; Inclusão social.

\begin{abstract}
The purpose of this article is to reflect about wheelchair dancer participation and social inclusion within the context of presentations and spectacles open to the public. We adopt qualitative research to enhance and complement investigation concerning study subject, analyzing interview applied to a group of twelve wheelchair dancers. We utilized analysis proposals to make discussion and reflexion about the dancers ansewers. The result of the worked out in details discussions about the dancers speech in wheelchairs detach the dance as artistic product and don"t put in focus the deficiency of the dancer but fortfy in the stage context and in one who has spectations relationship, a new social identify, the artistic identify.
\end{abstract}

\section{Keywords}

Disability; Wheelchair dance; Social inclusion.
Rev Bras Ativ Fis Saúde p. 440-448 DOI: http://dx.doi.org/10.12820/23171634.2012v17n5p440

1 Faculdade de Educação Física, Unicamp, Campinas, SP, Brasil 


\section{INTRODUÇÃO}

A deficiência sentida e percebida na vida de uma pessoa é o produto do entrelaçamento de sua história pessoal com o meio social onde vive. Sobre o indivíduo considerado deficiente recairá o estigma da "incapacidade", da "invalidez".

No que diz respeito à deficiência física, os sinais corporais conotativos da diferença da "normalidade" são particularmente visíveis. Ao pensarmos no corpo com deficiência Miranda ${ }^{16}$ diz que a forma corporal de cada um, quando não corresponde ao ideal de corpo vigente é também recusada e olhada, "de fora", como um inimigo que desafia os ideais da comunidade. Neste sentido as políticas de exclusão começam por excluir o próprio corpo.

As pessoas com deficiência física/motora foram vistas ao longo do tempo como incapazes de realizar atividades simples do $\operatorname{cotidiano}^{5}$ e a dança, pela sua ideologia, era vista como uma arte impossível de ser realizada por estas pessoas.

De acordo com Ferreira ${ }^{8}$, com relação à dança, existe uma ideologia específica construída histórica e culturalmente em nossa sociedade no que se refere ao tipo de corpo ideal para execução desta atividade artística, que sempre valorizou a ideia da superação, a beleza dos corpos e a plástica de movimentos. Considerando que a deficiência significa a antítese cultural do corpo saudável e apto, quando uma pessoa com deficiência, apresenta-se no papel de dançarino, é preciso ressaltar que esse papel vem sendo historicamente reservado para a glorificação de um corpo ideal.

No entanto, o que se vê na dança em cadeira de rodas é que o corpo deficiente e excluído se expressa quebrando paradigmas, despadronizando movimentos, construindo uma nova identidade, além de executar uma coreografia transformando gestos em linguagem da dança. Nesta modalidade a cadeira de rodas transforma-se de um símbolo de impotência a um objeto de desafio deixando de ser apenas um meio de locomoção, passando a ser uma possibilidade a mais de criação e uma nova proposta estética.

Neste sentido Tolocka ${ }^{22}$ diz que a possibilidade de dançar sobre uma cadeira de rodas vem contribuindo para mudanças sociais, que se referem à participação de pessoas com deficiência física na vida comunitária, e também na modificação do significado da cadeira de rodas dentro de uma sociedade, na qual a princípio tal cadeira era vista como sinônimo de imobilidade e incapacidade.

Ao relatar o impacto de um espetáculo de dança em cadeira de rodas na sociedade e a interação de bailarinos com e sem deficiência no palco simultaneamente, observa-se nestes contextos as oportunidades de inclusão e ampliação de relacionamentos sociais das pessoas envolvidas neste contexto. O espetáculo é visto como um espaço de interação e inclusão social entre dançarinos e expectadores.

$\mathrm{Na}$ perspectiva de Araújo ${ }^{21}$, inclusão é o resultado da soma de oportunidades bem sucedidas que são possibilitadas a qualquer cidadão. $\mathrm{E}$ a dança em cadeira de rodas é uma oportunidade para pessoas com deficiência física motora mostrarem suas potencialidades na forma de expressão artística ${ }^{12}$.

Johnstone ${ }^{11}$ considera a inclusão como um sentimento de pertencer a um grupo social ou lugar. De acordo com este autor, existe no ser humano um "sentido de lugar" que é um conceito que inclui sentimentos sobre onde é que cada um pertence, em relação aos outros. É um conceito com componentes simultaneamente objetivos e subjetivos, e assim, o conceito contemporâneo de lugar liga-se com as noções de inclusão.

Neste sentido Mattos ${ }^{14}$ diz que a dança, mesmo com coreografias e estilos diferentes, pode ser um exercício de procurar por meio da percepção sensorial e 
emocional, entrar em harmonia com a expressão de um grupo, estando, assim, cada integrante incluído, aprendendo a respeitar a diversidade e peculiaridade de cada participante. Sendo assim, poder-se-ia dizer que os dançarinos em cadeira de rodas encontram o seu lugar dentro da categoria de artistas dançarinos inseridos nos grupos de dança.

Entende-se a dança em cadeira de rodas como uma modalidade que utiliza como instrumento a cadeira de rodas, podendo ser de caráter artístico/recreativo ou competitivo. O praticante realiza os movimentos com auxílio desse instrumento, estando em interação com outros dançarinos, sendo estes, usuários ou não de cadeira de rodas ${ }^{12}$.

O presente artigo aborda reflexões acerca dos sentimentos e percepções dos dançarinos com deficiência física motora nas relações sociais estabelecidas no contexto de ensaios, apresentações e espetáculos de dança abertos ao público e no contato com os expectadores.

\section{MÉTODOS}

A presente investigação é caracterizada como pesquisa qualitativa onde buscamos alcançar os objetivos por meio de pesquisa bibliográfica e de campo.

A pesquisa de campo foi aprovada pelo Comitê de Ética em Pesquisa CEP/ FCM/ UNICAMP, com parecer número 910/2009 que consistiu na realização de entrevistas com doze dançarinos usuários de cadeira de rodas.

Para a realização de uma análise detalhada dos dados coletados nas entrevistas utilizamos as contribuições de Bardin² sobre a análise de conteúdo das narrativas, enquanto técnica científica e sistematizada, procurando um alinhamento do referencial teórico com a fonte oral.

\section{População}

Para a aplicação da técnica escolhida definiu-se, como universo da pesquisa, 12 (doze) dançarinos de ambos os sexos, de diferentes faixas etárias e diversas regiões do Brasil.

Os sujeitos da pesquisa foram agrupados da seguinte forma:

- Pessoas em condição de deficiência motora congênita;

- Pessoas em condição de deficiência motora adquirida.

- Todos os dançarinos deveriam ser integrantes de grupos ou companhias de dança em cadeira de rodas

- Ter participado de espetáculos ou competições abertas ao publico.

\section{Procedimentos}

A natureza do corpus desta pesquisa foi constituída por material oral, coletado em entrevistas realizadas por contato direto da entrevistadora com a população de estudo acima citada. Utilizou-se uma questão aberta, gravada e transcrita na íntegra.

Os locais das entrevistas foram: a Sede do Centro de Dança Integrado (CEDAI) da cidade de Campinas, local onde os dançarinos em cadeira de rodas desenvolviam suas atividades e ensaios semanalmente; e o 5 Simpósio de Dança em Cadeira de Rodas na cidade de Juiz de Fora, evento que reuniu grande número de dançarinos em cadeira de rodas de diversas regiões do país.

$\mathrm{Na}$ sequência, apresentamos a questão utilizada nas entrevistas dos dançarinos. 
- Questão: Como você percebe sua inclusão e participação na sociedade no contexto dos espetáculos de dança em cadeira de rodas?

\section{RESULTADOS}

Para melhor apresentar os processos metodológicos realizados durante a análise dos dados foram organizadas na Tabela 1 , as informações que caracterizam o perfil dos doze dançarinos selecionados.

Tabela 1 - Perfil representativo dos 12 (doze) dançarinos entrevistados

\begin{tabular}{lccl}
\hline Dançarino & Idade & Sexo & Deficiência \\
\hline 1 & 34 & Masculino & Adquirida \\
\hline 2 & 19 & Feminino & Adquirida \\
\hline 3 & 29 & Masculino & Congênita \\
\hline 4 & 22 & Masculino & Adquirida \\
\hline 5 & 42 & Masculino & Adquirida \\
\hline 6 & 36 & Masculino & Adquirida \\
\hline 7 & 71 & Feminino & Congênita \\
\hline 8 & 28 & Feminino & Congênita \\
\hline 9 & 27 & Feminino & Congênita \\
\hline 10 & 23 & Feminino & Congênita \\
\hline 11 & 19 & Feminino & Congênita \\
\hline 12 & 22 & Feminino & Congênita \\
\hline
\end{tabular}

Os entrevistados apresentam uma variação de idade: entre 19 e 71 anos, sendo $58,3 \%$ do sexo feminino.

Através do levantamento dos indicadores tendo como base os depoimentos dos dançarinos, pôde-se então eleger as categorias apresentadas a seguir. Essas categorias encontradas nos discursos dos dançarinos nos permitem a demarcação da metodologia de análise de conteúdo ${ }^{2}$ e a interpretação dos dados coletados, com base no referencial teórico.

\section{Categorias}

- Reconhecimento Social

- Superação

- Normalidade

- Reconhecimento das Potencialidades/Competências

- Relacionamentos Interpessoais.

\section{DISCUSSÃO}

O presente estudo procurou refletir sobre a participação e inclusão social dos dançarinos em cadeira de rodas no contexto de apresentações e espetáculos abertos ao público, partindo das opiniões e sentimentos dos próprios dançarinos protagonistas deste estudo.

Em função da riqueza de aspectos levantados durante as entrevistas definiu-se por apresentar a discussão dos resultados, com base em cada categoria encontrada nos depoimentos. 


\section{Reconhecimento social}

O Reconhecimento Social manifesta-se nos discursos dos entrevistados 1, 4, e 7 que afirmam serem vistos não pela condição da deficiência que estigmatiza, mas sim como artistas, ou seja, passaram a ser conhecidos pela identidade de dançarino e reconhecidos por suas potencialidades artísticas. A percepção de sentir-se reconhecido socialmente por meio da dança pode ser destacada através das afirmações abaixo:

Há uma mudança na visão social, quando as pessoas vêm um deficiente dançar. Se ele pode dançar ele poderá fazer tudo o que ele quiser. (Dançarino 4 - 22 anos)

Hoje as pessoas me conhecem como H. P dançarina, elas poderiam me conhecer como aquela moça deficiente na cadeira de rodas. (Dançarina7- 71 anos)

A dança em cadeira de rodas é uma modalidade artística que valoriza a diferença, a interpretação, a criatividade, os espetáculos artísticos destacam a arte e o produto artístico, não enfocando a deficiência. Ela existe, mas no contexto do palco, os dançarinos fortalecem uma nova identidade social, a identidade artística.

Segundo Ferreira ${ }^{7}$, os dançarinos ao realizarem seus gestos corporais estão se construindo menos impotente face ao real, assim, a importância na escolha da pessoa com uma condição de deficiência em desempenhar a atividade da dança está ligada ao sentimento de competência, a construção de novos sentidos e identificações face à sociedade a que ele pertence

Pode-se observar, através do discurso dos entrevistados, que a dança provocou uma nova visão social deles para com a sociedade e da sociedade em relação a eles. Os dançarinos com deficiência sentiram -se vistos como pessoas capazes de realizações e transformações em sua realidade cotidiana.

\section{Superação}

A Superação manifesta-se claramente no discurso do entrevistado 2, cujo os sentidos se expressam sob o domínio dos limites e da perseverança, assim manifestados:

“Conseguimos superar muitos obstáculos”. (Dançarino 2-19 anos)

De acordo com Cunha ${ }^{5}$, os discursos apresentados pelos dançarinos em cadeira de rodas, pertencem a um imaginário predominantemente heróico, no qual os heróis aventureiros passam grande parte de suas vidas cumprindo tarefas desafiantes, sobrevivendo aos sacrifícios para, então, retornarem renovados ao cotidiano de suas vidas. Neste sentido percebe -se que a capacidade que o indivíduo tem para se auto-influenciar, por meio de desafios que coloca e da reação avaliativa de seus rendimentos e realizações, constitui um mecanismo cognitivo fundamental de motivação. $\mathrm{Na}$ dança em cadeira de rodas, o dançarino se arrisca em busca da transcendência, enfrentando desafios, transpondo limites, alimentando o desejo de prosseguir ${ }^{21}$.

\section{Normalidade}

Nos discursos dos dançarinos entrevistados 3 e 8 percebe -se que existe um desejo de serem "olhados e tratados", não somente pela condição da diferença, mas como seres humanos que possuem sentimentos e capacidades. $\mathrm{O}$ dançarino 3 utiliza o conceito de igualdade e o dançarino 8 utiliza o conceito de normalidade para expressar que podem viver uma vida dentro dos padrões. Em ambos os discursos, 
percebe-se a necessidade de transpor as diferenças para mostrar sua humanidade e capacidade de viver uma vida plena de realizações, assim como as pessoas sem deficiência em seus cotidianos.

"Eu sinto que as pessoas passam a ver o deficiente como uma pessoa igual".

"As pessoas vêm que não há diferença". (Dançarino 3 -29 anos)

"Quando estou dançando procuro estar passando que existe uma pessoa dentro da pessoa portadora de deficiência, que tem sentimentos e que pode viver uma vida normal". (Dançarina 8-28 anos)

O referencial teórico sobre o conceito de normalidade está baseado no mito do corpo perfeito. Os termos "deficiente", "desviante", "diferente" e "anormal", traduzem muitas coisas, além dos gestos e comportamentos normalmente impostos para a manutenção da vida de qualquer ser humano.

Segundo Sassaki ${ }^{19}$, acredita-se como "normal" a pessoa sem nenhuma condição de deficiência. $\mathrm{O}$ autor complementa ainda que existe na sociedade uma divisão, entre o que é "normal" e "anormal", entre "comum" e "incomum", entre "iguais" e "diferentes". $\mathrm{Carmo}^{4}$ atribui o conceito de deficiência a toda e qualquer pessoa que apresente incapacidade para realizar gestos, atividades ou comportamentos considerados "normais".

Entre as concepções teóricas existentes, optamos por apresentar a concepção de deficiência como uma variação própria da espécie humana. De acordo com Diniz ${ }^{6}$ nesta concepção, "ser deficiente é experimentar um corpo fora da norma", ou seja, a ideia de deficiência somente ocorre ou se apresenta "com uma representação de o que seria o corpo sem a deficiência”.

Isto porque, conforme assinala Goffman ${ }^{10}$ essa diferença tem teor marcadamente social: "a diferença, em si, deriva da sociedade, pois antes que uma diferença seja importante ela deve ser coletivamente conceitualizada pela sociedade como um todo"

Para Diniz 6 :

Ao contrário do que se imagina, não há como descrever um corpo com deficiência como anormal. A anormalidade é um julgamento estético e, portanto, um valor moral sobre os estilos de vida. Há quem considere que um corpo cego é algo trágico, mas há também quem considere que essa é uma entre várias possibilidades para a existência humana.

Constata-se no discurso dos dançarinos que a crença da sociedade majoritária, que define o que é o "normal" e "anormal", "diferente" e "desigual", foi incorporada pelos dançarinos com deficiência fazendo parte do seu cotidiano, de tal maneira que o normal e o anormal não se encontram dentro da pessoa, mas fora dela, sendo, portanto, aquilo que os outros percebem nessa pessoa.

Observa-se nestes discursos que a dança em cadeira de rodas proporciona uma resignificação da deficiência, um novo olhar do expectador em relação à pessoa com deficiência. Entretanto, não se pode silenciar que o discurso dos entrevistados mostra, uma grande necessidade de "sentir- se visto e tratado com dignidade" como todo ser humano que possui sentimentos, anseios e potencialidades, uma vez que, o olhar sobre a diferença e o referencial de normalidade, faz-se ainda muito presente em nossa sociedade.

\section{Reconhecimento das Potencialidades / Competências}

O Reconhecimento das Potencialidades está diretamente ligado ao reconhecimen- 
to social, observamos neste estudo que o dançarino ao demonstrar suas habilidades artísticas corporais em cena, sente - se reconhecido socialmente. Destaca-se nos depoimentos dos dançarinos 4, 10 e 11, a importância de mostrar para a sociedade que são pessoas capazes de dançar e de realizar muitas atividades.

...Se ele pode dançar ele poderá fazer tudo o que ele quiser. (Dançarino 4 - 22 anos)

A dança permite mostrar as minhas possibilidades culturais e possibilidades de movimento. (Dançarina 10 - 23 anos)

Eu tenho capacidade para fazer isto e muito mais. (Dançarina 11 - 19 anos)

Beppler $^{3}$ aponta que os indivíduos têm necessidade de serem reconhecidos pelo grupo, pois, a partir deste reconhecimento, eles são capazes de formar uma imagem de si próprios.

Segundo Poloni ${ }^{17}$ a importância de sentir - se reconhecido, embora seja mais comum entre os homens que continuamente vivem em tensão de serem valorizados por suas funções e desempenhos, parece mais acentuada entre as pessoas com deficiência.

Para Gaio 9 as pessoas que nasceram ou se tornaram diferentes em sua estrutura corporal, são igualmente capazes e gritam por liberdade moral e social. Elas querem mostrar-se, realizar todas as atividades possíveis e imagináveis.

Assim, na dança em cadeira de rodas, através do ato de estarem em cena, os dançarinos podem mostrar talentos, expressões e potenciais, valorizando suas aptidões pessoais e artísticas. Potenciais estes que são constantemente confirmados e reforçados pela reação positiva do expectador, como por exemplo a intensidade dos aplausos e diálogos possíveis estabelecidos no contexto pós-espetáculos entre artista e o público presente.

\section{Relacionamentos Interpessoais}

Os indicadores do discurso das dançarinas 9 e 10 expressam uma melhoria nos relacionamentos interpessoais, no convívio social e na percepção do mundo.

As pessoas quando te veem depois da apresentação te dão retorno.

Você fica fechado no seu mundinho em casa.

Você vai para fora e passa a ser uma pessoa diferente e

E passa a ver as coisas diferentes. (Dançarina 9 - 27 anos)

A dança me abriu as portas com as outras pessoas e até comigo mesma.

Para eu saber lidar com todo mundo á minha volta.

Fiquei mais solta, passei a conversar mais com as pessoas. (Dançarina10 - 23 anos)

Sobre estas afirmações, os estudos de Sato e Tolocka ${ }^{22}$, dizem que as pessoas praticantes da dança em cadeira de rodas passam a conviver com o mundo de forma diferente, uma vez que o movimento torna-se um mediador da possibilidade de inclusão. Percebe-se que houve uma modificação positiva no comportamento dos dançarinos após o contato com a modalidade e todo o contexto que envolve esta atividade.

Esta mudança de ações e comportamentos influenciou suas vidas cotidianas também em situações fora do contexto que envolve a dança. Neste sentido Michener et al. ${ }^{15}$ diz, que ao vivenciar o sucesso e os feedbacks positivos de seus desempenhos, há uma melhoria na auto - estima e como consequência, nos seus comportamento sociais. 
Sobre os depoimentos acima, foi possível observar que os relatos orais dos dançarinos com deficiência motora congênita e adquirida expressam sentimentos, percepções e variam de acordo com suas histórias de vida e experiências, porém não encontramos diferenças significativas nos discursos destes grupos que se refiram ao contexto da dança e ao fato de ter uma condição de deficiência congênita ou ter a deficiência adquirida como um acontecimento em determinada fase de suas vidas.

Ao refletir sobre as respostas dos dançarinos entrevistados, percebe-se que independente da variação de faixa etária e sexo, não há divergência de opiniões e sentimentos entre eles. Acreditamos que isto esteja associado ao prazer e a complexidade que a atividade da dança proporciona, principalmente no âmbito do sentimento de realização, visto que, na maioria dos casos, estas pessoas foram privadas de diversas oportunidades e vivências corporais, culturais e artísticas em seus cotidianos

Poder-se-ia afirmar que as categorias retiradas dos depoimentos e os recortes efetuados, foram capazes de subsidiar a importância da participação do dançarino em cadeira de rodas no contexto de espetáculos e apresentações abertas ao público, destacando-se o reconhecimento social, relações interpessoais, superação e reconhecimento de potencialidades.

\section{CONCLUSÕES}

Ao refletir sobre a participação dos dançarinos em cadeira de rodas nos espetáculos, verificou -se neste estudo que o ato de dançar transformou a relação destes artistas consigo mesmos, e como consequência, suas relações com o expectador e com a sociedade. Por ser uma atividade que não tem como propósito a segregação, a dança é construída e reconstruída a partir do referencial de seus praticantes, proporcionando um espaço de comunicação, afetividade e possibilidades, que favoreceram o reconhecimento e a inclusão social dos dançarinos entrevistados. Neste sentido, percebe-se que a dança frequentemente ultrapassa os limites do palco, refletindo diretamente nas vidas cotidianas dos dançarinos, em função dos benefícios que a prática da atividade oferece para esta população no âmbito de sua integridade física, psíquica e social.

Observou-se neste estudo que há uma aproximação entre expectadores e dançarinos estabelecida nos contextos pós-espetáculos, que normalmente ocorre com base no diálogo onde o artista poderá receber elogios e cumprimentos que confirmam o êxito de sua atuação e o reconhecimento de sua arte. Estas aproximações entre dançarino/expectador influenciaram positivamente as ações na vida cotidiana e na atuação social destes artistas que, muitas vezes, portam de suas histórias de vida, as marcas e o estigma da deficiência.

Neste sentido, podemos dizer que a atuação do dançarino com deficiência no espetáculo transforma a dança num espaço político público, onde emerge a identidade social de artista, pois ela transcende os limites do espaço privado e da intimidade do dançarino para o espaço público e a sociabilidade.

Dançar nas mais diferentes formas expressadas ou manifestadas traz significados que podem ser identificados somente pelas partes envolvidas e na maioria das vezes possibilitam muitas leituras como sendo também uma forma de gritar pela liberdade através da expressão do corpo, viver, sentir cada momento da música, dos corpos que se entrelaçam, da descoberta do individual e do coletivo, dos aplausos, do realizar e se fazer sujeito nos espetáculos e na identidade do papel de artista presente pela subjetividade do contexto da dança e da deficiência. 


\section{Contribuição dos Autores}

Todos os autores colaboraram para elaboração, revisão crítica, análise do conteúdo e aprovaram a versão final do manuscrito.

\section{Referências Bibliográficas}

1. Amaral R, Coelho A. Nem Santos nem Demônios: Considerações sobre a Imagem Social das Pessoas Ditas “Deficientes”. http://www.aguaforte.com/antropologia/urbanitas. Acessado em 20 de maio de 2010.

2. Bardin L. Análise de conteúdo. Lisboa: 70LDA, 1977.

3. Bepler L. Mudança organizacional e construção da identidade social. http://www.lepar7cta. pr.gov.br/Portfolio.nsf/FILE/trfinal.doc. Acessado em 16 de maio de 2010.

4. Carmo, A.A. Deficiência Física: a sociedade brasileira cria, recupera e discrimina. Brasília: Secretaria dos Desportos, 1991.

5. Cunha M. Dançando sobre rodas: refletindo sobre a aventura metafórica do corpo em movimento. In: Anais do V Simpósio de dança em cadeira de rodas. Juiz de Fora: CBDCR, 2005:38- 49 .

6. Diniz, D. O que é deficiência. São Paulo: Editora Brasiliense, 2007.

7. Ferreira, E. L. Dança em cadeira de rodas: os sentidos do movimento na linguagem não verbal. Brasília: SNE, 2002.

8. Ferreira EL. O corpo do possível. In: Ferreira E L, organizador. Dança artística e esportiva para pessoas com deficiência: multiplicidade, complexidade e maleabilidade corporal. Juiz de Fora: CBDCR, 2005.

9. Gaio R. Para além do corpo deficiente: histórias de vida. Jundiaí: Editora Fontoura, 2006.

10. Goffman E. Estigma: notas sobre a manipulação da identidade deteriorada. ed. Rio de Janeiro: Guanabara, 1988.

11. Johnstone D. Explorando os limites da inclusão de jovens com deficiência e o seu sentido de lugar. In: Perspectivas sobre a inclusão: da educação à sociedade. Porto: Porto Editora, 2003:197-208.

12. Krombholz, G., Rausch, H, Zimmer, M. Wheelchair Dance Sport. München : 2001. (+ videoStandard Section and Latin Section).

13. Lopes KF. Identidade Social e Auto Conceito do Dançarino em Cadeira de Rodas. Dissertação (Mestrado)-Faculdade de Educação Física, Universidade Estadual de Campinas, Campinas, 2011.

14. Mattos, E. Dança em cadeira de rodas: proposta inclusiva. In: Dança artística e esportiva para pessoas com deficiência. Juiz de Fora: CBDCR, 2005:35-44.

15. Michener, H A. O Eu e a identidade. São Paulo: Thomson, 2005.

16. Miranda, Para incluir todos os corpos. In: Dança e Educação em Movimento São Paulo: Cortez, 2003.

17. Poloni, R. As funções da experiência corporal da dança em cadeira de rodas: perspectiva dos professores e alunos. In: Anais do V Simpósio de dança em cadeira de rodas. Juiz de Fora: CBDCR, 2005:50-57.

18. Rocha Ferreira, MB. Reflexões sobre dança em cadeira de rodas. In: Interfaces da dança para pessoa com deficiência. Campinas: CBDCR, 2002:90-104.

19. Sassaki R. Inclusão: construindo uma sociedade para todos. 7 ed. Rio de Janeiro: WVA, 2007.

20. Silva, R, Araújo, P, Duarte E. Inclusão educacional: uma "roupa nova" para um "corpo velho". EFDeportes Revista Digital. http://www.efdeportes.com. Acessado em 02 de maio de 2011.

21. Silva, R, Seabra L, Araújo P. Educação Física Adaptada no Brasil: da História á Inclusão Educacional. São Paulo: Phorte, 2008.

22. Tolocka R. Dançar em cadeira de rodas: muito mais do que dançar com o que sobrou: Aspectos neurológicos do movimento executado por pessoa com lesão neuronal. In: Interfaces da dança para pessoa com deficiência. Campinas: CBDCR, 2002:26-32.

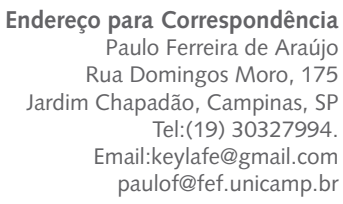

